\title{
Diversity and Distribution of Salmonella Isolated from Poultry Offal in Niger (West Africa)
}

\author{
Alio Sanda Abdelkader ${ }^{1, *}$, Samna Soumana Oumarou ${ }^{2}$, Inoussa Maman Maârouhi ${ }^{1}$, \\ Soumana Abdou Boubacar ${ }^{2}$, Moussa Hassane Ousseini ${ }^{1}$, Bakasso Yacoubou ${ }^{1}$ \\ ${ }^{1}$ Laboratory for Management and Valorization of Biodiversity at Sahel, Faculty of Science and Technology, University Abdou Moumouni of \\ Niamey, Niamey, Niger \\ ${ }^{2}$ Faculty of Agricultural Sciences and Environment, University of Tillaberi, Tillaberi, Niger
}

\author{
Email address: \\ aliosanda@yahoo.fr (A. S. Abdelkader) \\ ${ }^{*}$ Corresponding author
}

\section{To cite this article:}

Alio Sanda Abdelkader, Samna Soumana Oumarou, Inoussa Maman Maârouhi, Soumana Abdou Boubacar, Moussa Hassane Ousseini, Bakasso Yacoubou. Diversity and Distribution of Salmonella Isolated from Poultry Offal in Niger (West Africa). International Journal of Microbiology and Biotechnology. Vol. 4, No. 3, 2019, pp. 103-112. doi: 10.11648/j.ijmb.20190403.16

Received: July 11, 2019; Accepted: August 30, 2019; Published: September 18, 2019

\begin{abstract}
Objective: The aim of this study is to determine the prevalence and phenotype diversity of Salmonella isolated from poultry offal in Niger. Methodology and Results: A total of 155 poultries offal consisting of gizzard, liver and spleen were analyzed according to ISO 6579: 2002. Based on these different analyzes, high prevalence of Salmonella from $20 \%$ to $69 \%$ was found. Serotyping showed the predominance of Derby $42.37 \%$ followed by $S$. Hato $15.25 \%, S$. Chester $10.17 \%, S$. Agona 5.08\%, S. Suberu and S. Essen 3.39\% each, S. Hessarek and S. Kissangani 1.69\% each. Isolated Salmonella strains showed low resistance to antibiotics. Conclusion and perspective: Poultry offal for human consumption has high concentration of Salmonella. This is due to poor hygienic practices of poultry sellers. From these facts, awareness and training measures are necessary. Niger authorities must also build modern slaughterhouses and poultry markets in order to reduce the risk infectious proliferation of diseases such as gastroenteritis and food poisoning.
\end{abstract}

Keywords: Salmonella, Diversity, Serotypes, Poultry Offal, Niger

\section{Introduction}

Salmonella are one of the first causes of food contamination in developing countries as well as in industrialized ones. Food risk is little tolerated by the population and some zoonotic food pathogens are in the center of most concerns. Among pathogens, Salmonella was the second cause of bacterial food toxiinfections in Europe [1]. An over world epidemic bound to Enteritidis serovar of which the evident source still egg layer chicken began around the eighties. Since then, multi-resistant clones have emerged and their impact upon human health in terms of morbidity and mortality has been documented [2]. They, by the way, stand for public health issue and the community owes for that. Chicken business is considered as one of major sources of human contamination [3-4], whether fresh or undercooked foods as chicken meat, eggs and ovoproduct, charcuteries etc. [5-9]. In sub-Saharan Africa, Salmonella are one of the important causes of acute gastroenteritis and invasing infections. They cause 20 to $25 \%$ of mortality. Almost 70 million tons of poultry are produced per year, of which almost $85 \%$ are chicken. That's the second type of eaten meat over the world right after pig [10]. Food from animals, particularly chicken, are widely recognized as Salmonella sources due to wide spreading of Salmonella over gastrointestinal tract of chicken [11-14]. In Niger, Poultry farming is increasing. Avicole livestock is around 12196000 units in 2009 [15]. Also, family aviculture constitutes the main source of animal protein in rural areas in Niger [16]. The offal of poultry, particularly the gizzard and the liver are the top appreciated and much eaten in Niger but they are likely to contain pathogen germs such as the Salmonella [17-18]. Such top eaten products still remain unknown as far as their microbiological quality. In Niger, very little data are available on this topic. This study has been conducted to determine the prevalence of Salmonella in offal of poultry and to assess the distribution of the isolated serotype of these products 
in Niger.

\section{Materials and Methods}

\subsection{Presentation of Poultry Offal Collection Sites}

Collection of samples has been conducted in seven areas of Niger except Diffa area. In every area a chicken slaughtering site has been chosen (Table 1).

Table 1. Characteristics of study sites of poultry offal.

\begin{tabular}{llll}
\hline Regions & Sites & $\begin{array}{l}\text { Collection } \\
\text { dates }\end{array}$ & $\begin{array}{l}\text { Number of } \\
\text { samples }\end{array}$ \\
\hline Niamey & Wadata February 2016 & $27 / 02 / 2016$ & 18 \\
Tillabéri & Wadata August 2016 & $14 / 08 / 2016$ & 22 \\
Dosso & Stade & $17 / 03 / 2016$ & 20 \\
Maradi & Gaya Koirategui & $26 / 03 / 2016$ & 18 \\
Zinder & Ali Dan Sofo & $01 / 05 / 2016$ & 18 \\
Tahoua & Pantchis & $02 / 05 / 2016$ & 20 \\
Agadez & Maboya Amaré & $07 / 06 / 2016$ & 17 \\
Total & Sabon Gari & $08 / 06 / 2016$ & 22 \\
\hline
\end{tabular}
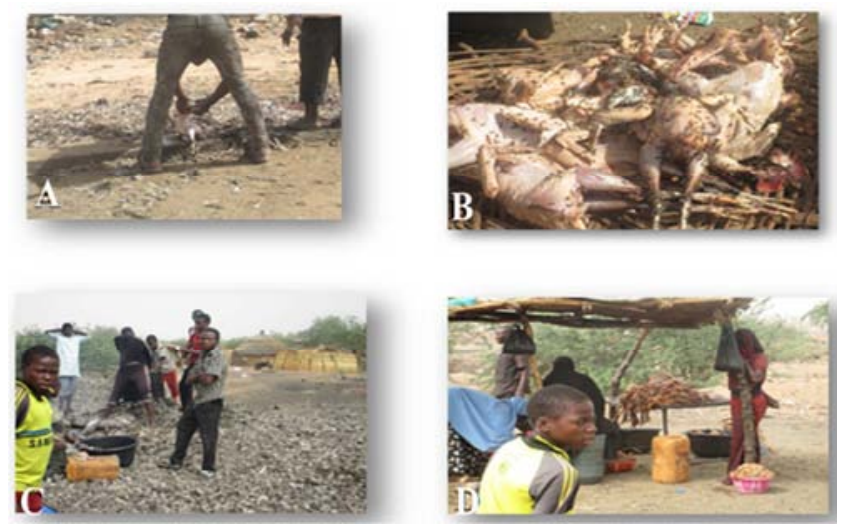

Figure 1. Poultry Slaughter sites in Niger.

A and B: Poultry slaughter sites of Sabon Gari Agadez, Niger; C and D: Poultry slaughter sites of Ali Dan Sofo Maradi, Niger. (Figures Alio et al., 2016).

\subsection{Poultry Offal Sampling}

The study has combined inquiries questionnaires and, sampling and analysis in laboratory. In every slaughter site, only samples of available poultry offal were collected (Figure 1). Samples were put in icebox at $4^{\circ} \mathrm{C}$ and are taken to the laboratory. Every sampling is accompanied by questionnaire. In sum 155 samples of poultry offal were collected.

\subsection{Microbiological Analyzes}

The microbiological analysis was done according to ISO 6579:2002 in 4 steps: pre-enrichment, enrichment, isolation and biochemical identification. The microbiological analysis for the research of Salmonella was realized on 155 poultry offal in order to determine the prevalence and different serotypes flowing in the poultry. Samples were sent to the laboratory in an isothermal thermos at $4{ }^{\circ} \mathrm{C}$ and treated in the day time. Then, they were placed on gelose
Mueller Hinton and incubated at $37^{\circ} \mathrm{C}$ for $18-24$ hours. Suspicions settlements were submitted to biochemical reactions by using gallery API $20 \mathrm{E}$ Enteric according to producers. Biochemical profiles have been converted into a numerical profile in other words a number that permits an easy transcription of all obtained for an organism and compared to list in the index. The 21 corresponding reactions were coded and separated by groups of three (3). A value 1, 2 or 4 is indicated for each of the reaction, giving a numerical code of 7 numbers. After biochemical tests, some strains were read and confirmed. The results were compared following a Ascending Hierarchical Classification (AHC). Binary chart were realized on the basis of the positivity or the negativity of biochemical tests. The similarity between strains is determined following the Euclidean index and a dendrogram illustrated this produced similarity. Moreover, the serotyping was made according to the schema of KAUFFMANN-WHITE (1934): The isolated pure culture on gelose was stereotyped by the direct agglutination technique on blade by following on a panel antisera $(\mathrm{O}, \mathrm{H}$ and $\mathrm{Vi})(\mathrm{Bio}-\mathrm{Rad} \AA)$. The determination of serotypes is the combination of antigenic formulas corresponding to the antigens "O" and "H» expressed during different agglutinations. All the isolates were tested for susceptibility to 18 different antimicrobial agents using the Mueller Hinton II Agar Diffusion Method (Bio-Rad France) according to EUCAST guidelines (European Committee on Antimicrobial Susceptibility Instructions). The antimicrobial disks used were ampicillin: AMP (10 $\mu \mathrm{g})$; amoxicillin: AML $(25 \mu \mathrm{g})$; amoxicillin + clavulanic acid: AMC (20/10 $\mu \mathrm{g})$; ceftazidime: CAZ $(30 \mu \mathrm{g})$; cefotaxime: CTX: $(30 \mu \mathrm{g})$; ceftriaxone: CRO $(30 \mu \mathrm{g})$; Cefepime: FEP: $(30 \mu \mathrm{g})$; chloramphenicol: C $(30 \mu \mathrm{g})$; gentamicin: GM: $(10 \mu \mathrm{g})$; aztreonam: AZT $(30 \mu \mathrm{g})$; amikacin: AK (30 $\mathrm{gg})$; Trimethoprim-sulfamethoxazole: SXT $(1.25 / 23.75 \mu \mathrm{g})$; nalidixic acid: NA $(30 \mu \mathrm{g})$; colistin: COL $(10 \mu \mathrm{g})$; ciprofloxacin: CIP $(5 \mu \mathrm{g})$; imipenem: IPM $(10 \mu \mathrm{g})$. Inhibition diameters of antibiotics were interpreted according to EUCAST. Finally, isolates resistant to ampicillin, amoxicillin, cefotaxime, ceftriaxone, gentamicin, nalidixic acid and ciprofloxacin were evaluated for Minimal Inhibitory Concentration (MIC) by the method of E - test according to the manufacturer's and European Committee on Antimicrobial Susceptibility Instructions (EUCAST) guidelines (EUCAST, 2013).

\subsection{Statistics Analyses}

The obtained data from the inquiry cards were treated with software XL-Stat version 2010 in other to determine the parameters impacting the presence of Salmonella. The results of bacteriological analysis were typed using the Microsoft Excel 2013 software for the preparations of graphics and charts. The PCORD 5 software was used to study biochemical similarity with the means of Ascending Hierarchical Classification (AHC). 


\section{Results}

\subsection{Characteristics and Practices Poultry Sellers}

The chart 2 presents the characteristics and practices of poultry sellers with regard to the most suitable parameters that can influence product quality. The sellers are exclusively male $(100 \%), 62.5 \%$ are lets old than 30 years, and are predominantly Hausa $(50 \%)$ and illiterate $(75 \%)$. Most of them $(75 \%)$ have never been sensitized about hygiene when manipulating poultry. Hand washing is practiced by $75 \%$ but after the activity of product dealing (50\%). No interrogated sellers have a medical examination last year.

Table 2. Characteristics and practices poultry sellers.

\begin{tabular}{|c|c|c|c|}
\hline Definition of the variable & Level & Number & Percentage (\%) \\
\hline \multirow{3}{*}{ Age (Years) } & $<30$ & 5 & 62.5 \\
\hline & $30-60$ & 3 & 37.5 \\
\hline & $>60$ & 0 & 0 \\
\hline \multirow{2}{*}{ Sex } & Man & 8 & 100 \\
\hline & woman & 0 & 0 \\
\hline \multirow{4}{*}{ Ethnic group } & Hausa & 4 & 50 \\
\hline & Zarma & 2 & 25 \\
\hline & Dendi & 1 & 12.5 \\
\hline & Kanuri & 1 & 12.5 \\
\hline \multirow{3}{*}{ Level of study } & Non scholarized & 6 & 75 \\
\hline & Primary & 1 & 12.5 \\
\hline & secondary & 1 & 12.5 \\
\hline \multirow{2}{*}{ Sensitization about Hygiene } & Yes & 2 & 25 \\
\hline & No & 6 & 75 \\
\hline \multirow{2}{*}{ Hands washing } & Yes & 6 & 75 \\
\hline & No & 2 & 25 \\
\hline \multirow{3}{*}{ Period of hands washing } & Before & 3 & 33.33 \\
\hline & During & 1 & 16.67 \\
\hline & After & 2 & 50 \\
\hline \multirow{2}{*}{ Medical examination } & Yes & 0 & 0 \\
\hline & No & 8 & 100 \\
\hline
\end{tabular}

\subsection{Prevalence of Isolated Salmonella of Poultry in Niger}

A total of 155 samples of poultry offal were analyzed. Salmonella spp were isolated in 59 (38.06\%) samples. the Figure 2 shows the distribution of isolation frequencies of Salmonella according to the regions of Niger. The reported frequencies vary between $69 \%$ in Niamey and 20\% in Zinder and Tillabéri.

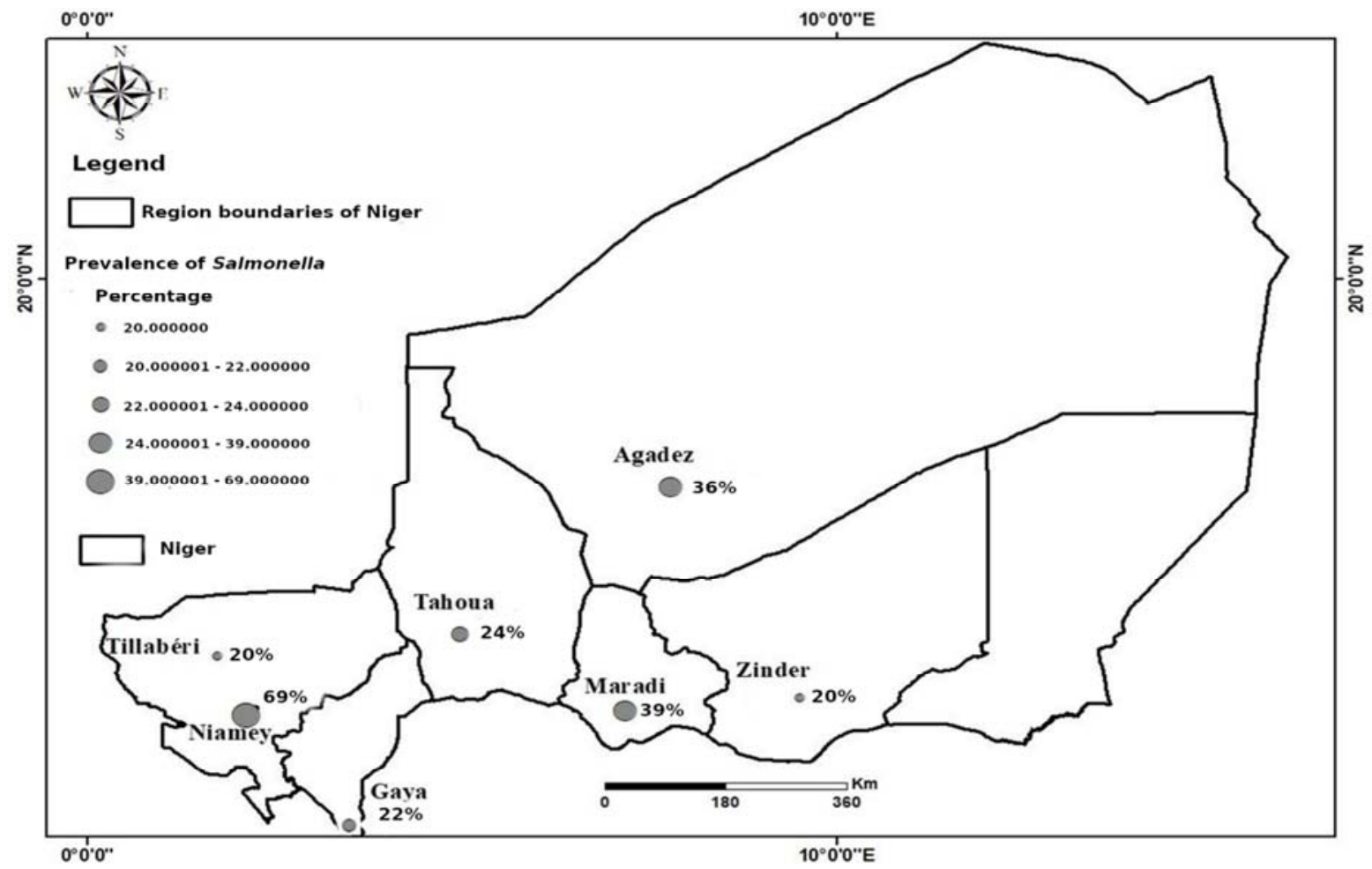

Figure 2. Distribution and frequencies of Salmonella isolated from poultry offal in the different regions of Niger. 


\subsection{Biochemical Characteristics of Isolated Strains from Poultry}

The grouping of Salmonella strains by Ascending Hierarchical Classification (AHC) on the basis of biochemical tests divides the 35 identified strains into two groups:

Group 1 is constituted of $94.29 \%$ (33/35), the majority of isolates. It is presented by the reading code for the gender determination: 6704752 which corresponds to an excellent identification of Salmonella spp. Strains in this group are characterized by their ability to degrade inositol ( $\mathrm{INO}^{+}$) which is an unusual biochemical characteristic in Salmonella.

Group 2 is constituted of $5.71 \%(2 / 35)$ of the isolates and have the reading code 6704552 for the genus determination which also corresponds to an excellent identification of Salmonella spp and differs from the group1 by $\mathrm{INO}^{-}$(Figure 3).

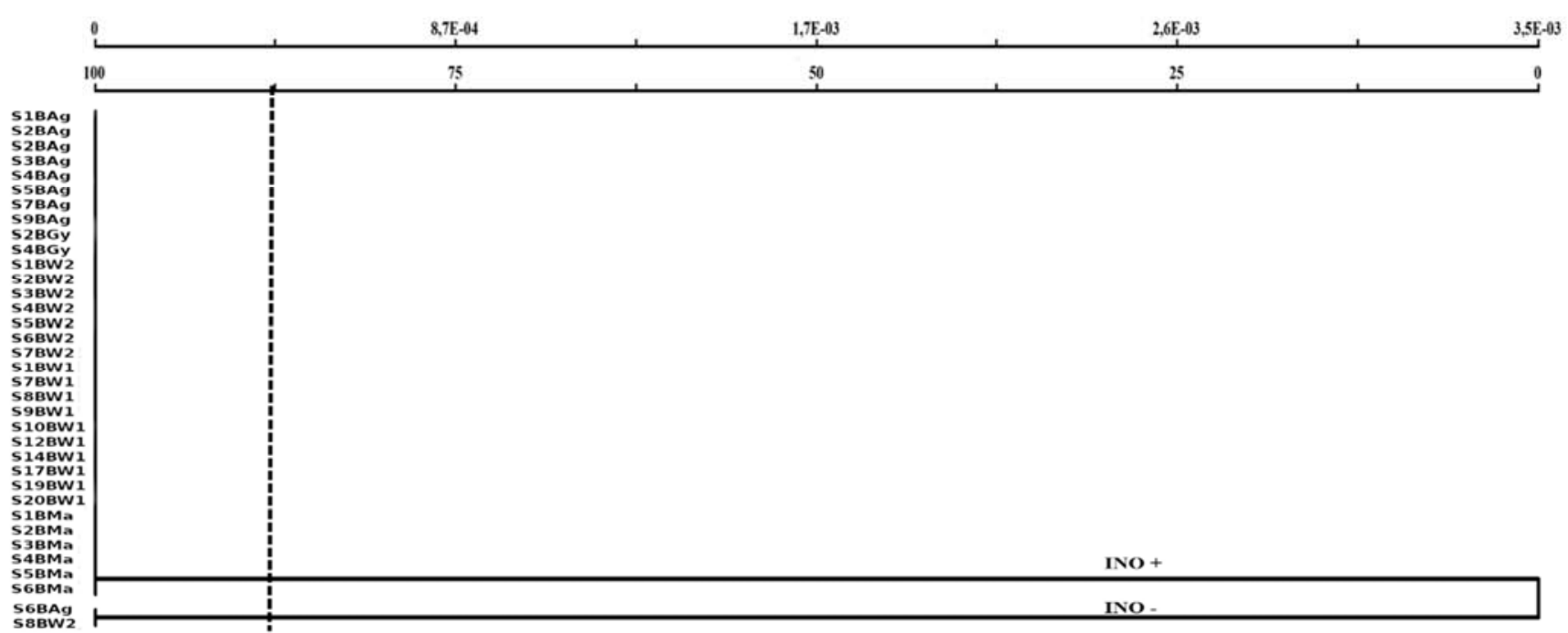

Figure 3. Ascending Hierarchical Classification (AHC) Dendrogram representative of the similarity of the biochemical characteristics of Salmonella isolated from poultry offal.

\subsection{Prevalence of Salmonella Serotypes Isolated from Poultry}

Serotyping Salmonella isolates from poultry offal allowed to observe eight (8) circulating serotypes in Niger (Figure 4). The predominant serotype is Salmonella Derby (42.37\%) and the least frequent are S. Hessarek (1.69\%) and S. Kissangani (1.69\%). However, $16.95 \%$ of the isolates could not be serotyped.

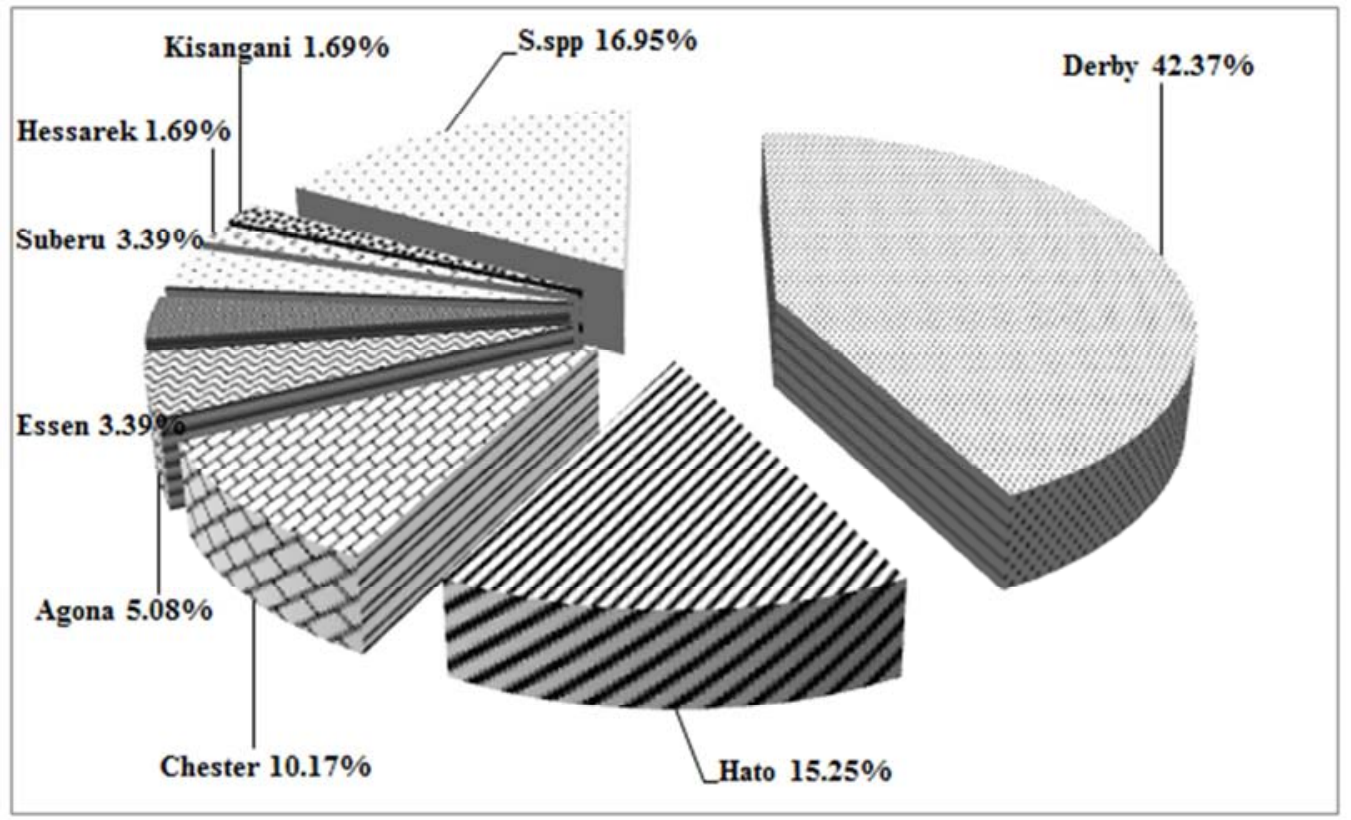

Figure 4. Percentage of different serotypes of Salmonella isolated from poultry offals. 


\subsection{Distribution of Antibiotic Sensitivity}

Isolated strains of Salmonella from poultry offal showed resistance to the family of penicillin A [ampicillin (11.43\%), amoxicillin (9.30\%), amoxicillin + clavulanic acid (6.98\%)]; polymyxin (colistin (45\%) and trimethoprimsulfamethoxazol $(9.30 \%)$. There is also noticed a strong diminution of sensitivity to antibiotic with strains presenting intermediate susceptibility to ampicillin (48.57\%), ofloxacin (11.63\%), amoxicillin + clavulanic acid $(9.3 \%)$, cefotaxim, ceftriaxone, amikacin respectively $(6.98 \%)$, trimethoprimsulfamethoxazol (4.65\%) and azetronam (2.33\%). All the Salmonella isolates were sensitive to ceftazidime, naladixic acid, ciprofloxacin and imipenem (Figure 5).

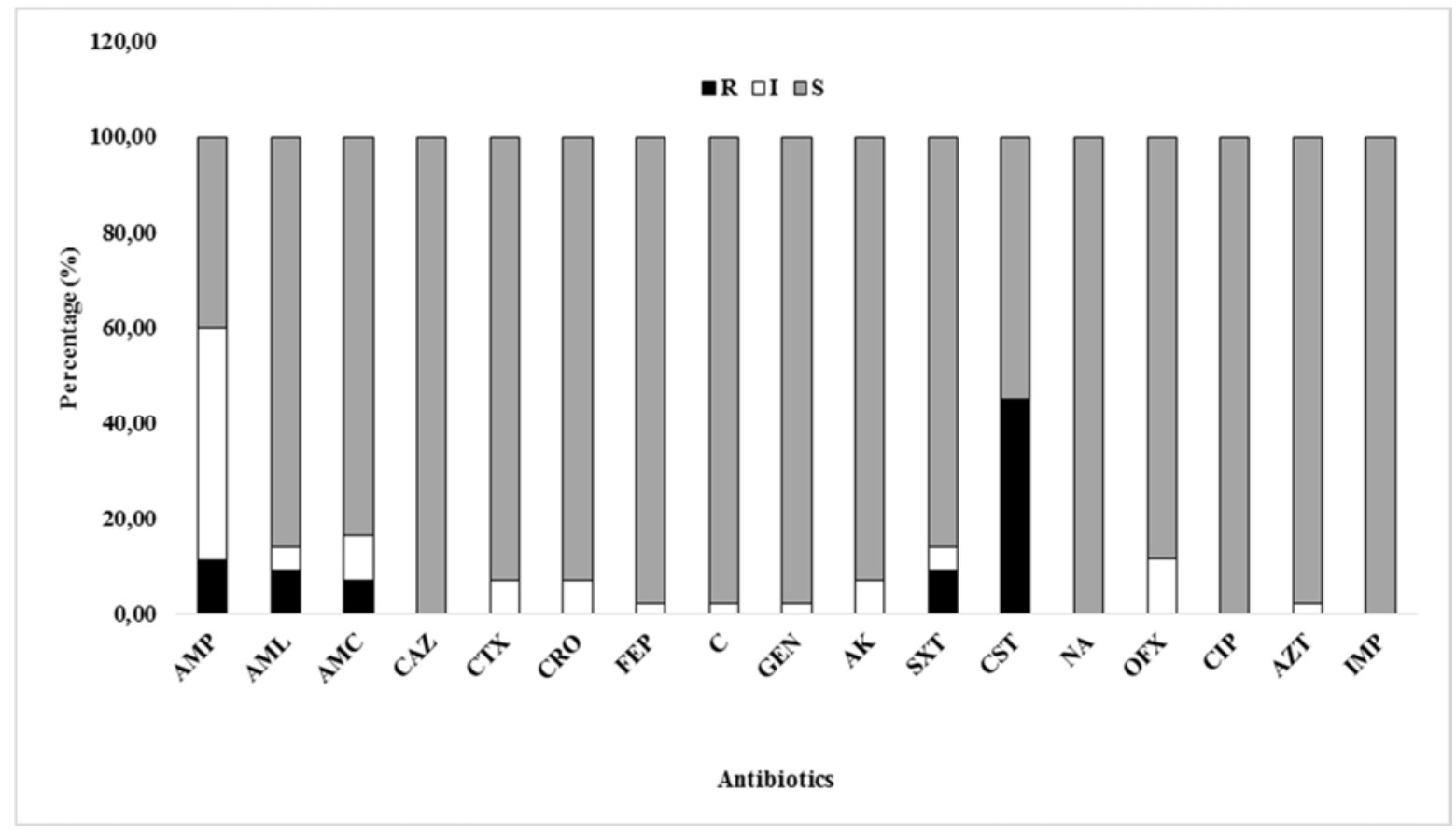

Figure 5. Frequency of antibiotic resistance of Salmonella strains isolated from poultry offal.

The black color corresponds to the resistance zone (R). The white color corresponds to the intermediate zone (I). The gray color corresponds to the sensitive zone (S). AMP: Ampicillin; AML: amoxicillin, AMC: amoxicillin + clavulanic acid; CAZ: ceftazidime; CTX: cefotaxime; CRO: Ceftriaxone; FEP: cefepime; CFM: cefixime; C: chloramphenicol; GEN: gentamicin; AZT: aztreonam; AK: amikacin SXT: trimethoprim-sulfamethoxazole; NA: nalidixic acid; COL: colistin; CIP: ciprofloxacin; IPM: imipenem.

\subsection{Distribution of Salmonella Serotypes Isolated from Poultry Offal According to Regions and Collection Areas}

Salmonella Derby is practically found in all regions of Niger with (62.5\%) in Niamey, (8.33\%) in Gaya, (12.5\%) in Agadez,
$(12.5 \%)$ in Tahoua and (4.1\%) in Maradi, with the exception of Zinder and Tillaberi. As Salmonella Hato in Niamey, Tillaberi, Gaya, Maradi and Agadez. Other serotypes have been found exclusively in one region: Salmonella Suberu in Niamey (Wadata August 2016), S. Hessarek and $S$. Kisangani in Zinder and $S$. Essen in Agadez (Table 3).

Table 3. Distribution of serotypes of isolated strains of Salmonella from poultry offal based on collection areas.

\begin{tabular}{|c|c|c|c|c|c|c|c|c|c|}
\hline \multirow{2}{*}{ Serotypes } & \multicolumn{2}{|l|}{ Niamey } & \multirow{2}{*}{$\begin{array}{l}\text { Dosso Gaya } \\
(n=4)\end{array}$} & \multirow{2}{*}{$\begin{array}{l}\text { Maradi } \\
(n=7)\end{array}$} & \multirow{2}{*}{$\begin{array}{l}\text { Zinder } \\
(n=4)\end{array}$} & \multirow{2}{*}{$\begin{array}{l}\text { Agadez } \\
(n=10)\end{array}$} & \multirow{2}{*}{$\begin{array}{l}\text { Tahoua } \\
(n=4)\end{array}$} & \multirow{2}{*}{$\begin{array}{l}\text { Tillabéri } \\
(n=4)\end{array}$} & \multirow{2}{*}{ Total } \\
\hline & Wadata $(n=19)$ & Wadata $(n=7)$ & & & & & & & \\
\hline Derby & $14(73,68)$ & $1(14,29)$ & $2(50)$ & $1(14,29)$ & $-(-)$ & $3(30)$ & $3(75)$ & $-(-)$ & 24 \\
\hline Hato & $4(21,05)$ & $-(-)$ & $1(25)$ & $1(14,29)$ & $-(-)$ & $1(10)$ & $-(-)$ & $1(25)$ & 8 \\
\hline Chester & $-(-)$ & $4(57,14)$ & $-(-)$ & $-(-)$ & $2(50)$ & $-(-)$ & $-(-)$ & $-(-)$ & 6 \\
\hline Suberu & $-(-)$ & $2(28,57)$ & $-(-)$ & $-(-)$ & $-(-)$ & $-(-)$ & $-(-)$ & $-(-)$ & 2 \\
\hline Agona & $-(-)$ & $-(-)$ & $1(25)$ & $-(-)$ & $-(-)$ & $-(-)$ & $1(25)$ & $1(25)$ & 3 \\
\hline Kisangani & $-(-)$ & $-(-)$ & $-(-)$ & $-(-)$ & $1(25)$ & $-(-)$ & $-(-)$ & $-(-)$ & 1 \\
\hline Essen & $-(-)$ & $-(-)$ & $-(-)$ & $-(-)$ & $-(-)$ & $2(20)$ & $-(-)$ & $-(-)$ & 2 \\
\hline Salmonella $\mathrm{spp}$ & $1(5,26)$ & $-(-)$ & $-(-)$ & $5(71,43)$ & $-(-)$ & $4(40)$ & $-(-)$ & $2(50)$ & 12 \\
\hline
\end{tabular}

-: zero (0). 


\subsection{Frequency of Antibiotic Resistance of Salmonella Serotypes Isolated from Poultry Offal}

The resistance frequencies of Salmonella serotypes are summarized in Table 4. The Derby, Chester and Salmonella Spp serotypes (OMA, OMB, OMC, OMD-) were resistant to four (4) antibiotics. Salmonella Derby and Salmonella Spp (OMA, OMB, OMC, OMD -) presented the resistance profile according to AMP, AML, AMC, CST and Salmonella Chester: AML, AMC, SXT, CST.
Salmonella Hato and $S$. Hessarek were resistant to three (3) antibiotics. Salmonella Hato presented the resistance profile AMP, SXT, CST and $S$. Hessarek, resistance profile AMP, AML, CST. Two serotypes presented a resistance profile only to colistin, it is $S$. Essen and $S$. Suberu. Most serotypes were resistant to colistin. The percentage of resistance to colistin was between $28.57 \%$ for the $S$. Chester serotype and $100 \%$ for the $S$. Essen and $S$. Suberu serotypes.

Table 4. Frequency of antibiotic resistance of Salmonella serotypes isolated from poultry offal.

\begin{tabular}{|c|c|c|c|c|c|c|c|c|}
\hline \multirow{2}{*}{ Serotypes } & \multicolumn{8}{|c|}{ Antibiotics } \\
\hline & AMP & AML & AMC & CAZ & CTX & CRO & CFM & FEP \\
\hline Derby & $3(23,08)$ & $2(15,38)$ & $1(7,69)$ & $-(-)$ & $-(-)$ & $-(-)$ & $-(-)$ & $-(-)$ \\
\hline Chester & $-(-)$ & $1(14,29)$ & $1(14,29)$ & $-(-)$ & $-(-)$ & $-(-)$ & $-(-)$ & $-(-)$ \\
\hline Hato & $1(16,67)$ & $-(-)$ & $-(-)$ & $-(-)$ & $-(-)$ & $-(-)$ & $-(-)$ & $-(-)$ \\
\hline Hessarek & $1(33,33)$ & $1(33,33)$ & $-(-)$ & $-(-)$ & $-(-)$ & $-(-)$ & $-(-)$ & $-(-)$ \\
\hline Suberu & $-(-)$ & $-(-)$ & $-(-)$ & $-(-)$ & $-(-)$ & $-(-)$ & $-(-)$ & $-(-)$ \\
\hline Agona & $-(-)$ & $-(-)$ & $-(-)$ & $-(-)$ & $-(-)$ & $-(-)$ & $-(-)$ & $-(-)$ \\
\hline Kisangani & $-(-)$ & $-(-)$ & $-(-)$ & $-(-)$ & $-(-)$ & $-(-)$ & $-(-)$ & $-(-)$ \\
\hline OMA, OMB, OMC, OMD -(-) & $3(33,33)$ & $1(11,11)$ & $1(11,11)$ & $-(-)$ & $-(-)$ & $-(-)$ & $-(-)$ & $-(-)$ \\
\hline ND & $-(-)$ & $-(-)$ & $-(-)$ & $-(-)$ & $-(-)$ & $-(-)$ & $-(-)$ & $-(-)$ \\
\hline
\end{tabular}

Table 4. Continue.

\begin{tabular}{|c|c|c|c|c|c|c|c|c|c|c|c|}
\hline \multirow{2}{*}{ Serotypes } & \multicolumn{11}{|c|}{ Antibiotics } \\
\hline & C & GEN & AK & SXT & CST & NA & OFX & CIP & $\mathbf{A Z T}$ & IMP & Total \\
\hline Derby & $-(-)$ & $-(-)$ & $-(-)$ & $-(-)$ & $7(53,85)$ & $-(-)$ & $-(-)$ & $-(-)$ & $-(-)$ & $-(-)$ & 13 \\
\hline Chester & $-(-)$ & $-(-)$ & $-(-)$ & $3(42,86)$ & $2(28,57)$ & $-(-)$ & $-(-)$ & $-(-)$ & $-(-)$ & $-(-)$ & 7 \\
\hline Hato & $-(-)$ & $-(-)$ & $-(-)$ & $1(16,67)$ & $4(66,67)$ & $-(-)$ & $-(-)$ & $-(-)$ & $-(-)$ & $-(-)$ & 6 \\
\hline Hessarek & $-(-)$ & $-(-)$ & $-(-)$ & $-(-)$ & $1(33,33)$ & $-(-)$ & $-(-)$ & $-(-)$ & $-(-)$ & $-(-)$ & 3 \\
\hline Suberu & $-(-)$ & $-(-)$ & $-(-)$ & $-(-)$ & $1(100)$ & $-(-)$ & $-(-)$ & $-(-)$ & $-(-)$ & $-(-)$ & 1 \\
\hline Agona & $-(-)$ & $-(-)$ & $-(-)$ & $-(-)$ & $-(-)$ & $-(-)$ & $-(-)$ & $-(-)$ & $-(-)$ & $-(-)$ & 0 \\
\hline Kisangani & $-(-)$ & $-(-)$ & $-(-)$ & $-(-)$ & $-(-)$ & $-(-)$ & $-(-)$ & $-(-)$ & $-(-)$ & $-(-)$ & 0 \\
\hline OMA, OMB, OMC, OMD -(-) & $-(-)$ & $-(-)$ & $-(-)$ & $-(-)$ & $4(44,44)$ & $-(-)$ & $-(-)-(-)$ & $-(-)-(-)$ & $-(-)$ & $-(-)$ & 9 \\
\hline ND & $-(-)$ & $-(-)$ & $-(-)$ & $-(-)$ & $-(-)$ & $-(-)$ & $-(-)$ & $-(-)$ & $-(-)$ & $-(-)$ & 0 \\
\hline
\end{tabular}

AMP: Ampicillin; AML: amoxicillin, AMC: amoxicillin + clavulanic acid; CAZ: ceftazidime; CTX: cefotaxime; CRO: Ceftriaxone; FEP: cefepime; CFM: cefixime; C: chloramphenicol; GEN: gentamicin; AZT: aztreonam; AK: amikacin; SXT: trimethoprim-sulfamethoxazole; NA: nalidixic acid; COL: colistin; CIP: ciprofloxacin; IPM: imipenem.; -: zero (0).

\subsection{Study of Similarity of Antibiotic Resistance Patterns Between Isolated Strains of Salmonella from Poultry}

Results of antibiotic profiles of isolated strains from poultry were submitted to AHC (Ascending Hierarchical Classification) analysis to visualize the similarity of the strains. It allowed to individualize six (6) groups (Figure 6):

Group 1: constituted of 40 strains. They are characterized by sensitivity to all antibiotics;

Group 2: constituted of 2 strains. They were characterized by ampicillin resistance compared to group 1 ;
Group 3: constituted of 2 strains. They differ from those of group 1 by resistance to colistin;

Group 4: constituted of 4 strains which differ from group 3 by the resistance to ampicillin, amoxicillin, amoxicillin + clavulanic acid and trimethoprim-sulfamethoxazole;

Group 5: constituted of 4 strains. They are characterized by the resistance to colistin;

Group 6: constituted of a single strain. They are characterized by the resistance to ampicillin, with amoxicillin, amoxicillin + clavulanic acid and colistin. 


\begin{tabular}{|c|c|c|}
\hline & Serotypes & Resistance profils \\
\hline Derby(S1BW1) & Derby (S1BW1) & 0 \\
\hline Hato(S7BW1) & Hato(S7BW1) & 0 \\
\hline Hato(S8BW1) & Hato(S8BW1) & 0 \\
\hline Hato(S3BGy) & Hato(S3BGy) & 0 \\
\hline OMA,OMB,OMC,OMD-(S6Ma) & OMA,OMB,OMC,OMD-(S6BMa) & 0 \\
\hline ND(S6BAg) & ND(S6BAg) & 0 \\
\hline $\begin{array}{l}\text { Derby(S14BW) } \\
\text { Derby(S20BWI) }\end{array}$ & $\begin{array}{l}\text { Derby(S14BW1) } \\
\text { Derby(S2OBW1) }\end{array}$ & $\begin{array}{l}0 \\
0\end{array}$ \\
\hline Derby(S2BW1) & Derby (S2BW1) & 0 \\
\hline Derby(S3BW1) & Derby (S3BW1 & 0 \\
\hline Hato(S4BW1) & Hato(S4BW1) & 0 \\
\hline Derby(S6BW1) & Derby (S6BW1) & 0 \\
\hline Derby(S13BW1) & Derby(S13BW1) & 0 \\
\hline Derby(S16BW1) & Derby(S16BW1) & 0 \\
\hline Derby(S17BW1) & Derby(S17BW1) & 0 \\
\hline Hato(S5BAg) & Hato(S5BAg) & 0 \\
\hline $\begin{array}{l}\text { Derby(S2BTa } \\
\text { Hato(S1BTi) }\end{array}$ & Derby(S2BTa) & 0 \\
\hline $\begin{array}{l}\text { Hato(S1BTi) } \\
\text { Agona(S2BTi) }\end{array}$ & Hato(S1BTi) & $\begin{array}{l}0 \\
0\end{array}$ \\
\hline & Agona(S2BTi) & 0 \\
\hline Derby(S15BW1) & Derby(S15BW1) & 0 \\
\hline Derby(S18BW1) & Derby(S18BW1) & 0 \\
\hline $\begin{array}{l}\text { Agona(S4BTa) } \\
\text { OMA,OMB,OMC,OMD-(S3Ti) }\end{array}$ & Agona(S4BTa) & $\begin{array}{l}0 \\
0\end{array}$ \\
\hline & OMA,OMB,OMC,OMD-(S3BTi) & 0 \\
\hline Derby(S10BW1) & Derby(S10BW1) & 0 \\
\hline Agona(S1BGy) & Agona(S1BGy) & 0 \\
\hline Derby(S2BGy) & Derby(S2BGy) & 0 \\
\hline Derby(S4BMa) & Derby(SABMa) & 0 \\
\hline OMA,OMB,OMC,OMD-(S7BMa) & OMA,OMB,OMC,OMD-(S7BMa) & 0 \\
\hline Chester(S1BZr) & Chester(S1BZr) & 0 \\
\hline Kisangani(S2BZr) & Kisangani(S2BZr) & 0 \\
\hline Chester(S4BZr) & Chester(S4BZr) & 0 \\
\hline Derby(S1BAg) & Derby(S1BAg) & 0 \\
\hline Derby(S7BAg) & Derby(S7BAg) & 0 \\
\hline Essen(S8BAg) & Essen(S8BAg) & 0 \\
\hline ND(S9BAg） & ND(S9BAg) & 0 \\
\hline Hato(S5BMa) & Hato (S5BMa) & 0 \\
\hline OMA,OMB,OMC,OMD-(S4BAg) & OMA,OMB,OMC,OMD-(S4BAg) & 0 \\
\hline Derby(S4BGy) & Derby(SABGy) & 0 \\
\hline OMA,OMB,OMC,OMD-(S3BAg) & OMA,OMB,OMC,OMD-(S3BAg) & 0 \\
\hline Hato(SBW1) & Hato (SBW1) & 0 \\
\hline $\begin{array}{l}\text { Derby(S19BW1) } \\
\text { OMA,OMB,OMC,OMD-(S4BTi) }\end{array}$ & $\begin{array}{l}\text { Derby(S19BW1) } \\
\text { OMA,OMB,OMC,OMD-(S4BTi) }\end{array}$ & $\begin{array}{l}\text { AMP } \\
\text { AMP }\end{array}$ \\
\hline Derby(S9BW1) & Derby(S9BW1) & AMP,CST \\
\hline Derby(S2BAg) & Derby(S2BAg) & AMP \\
\hline Derby(S1BMa) & Derby(S1BMa) & AMLAMC,CST \\
\hline Hessarek(S3BZr) & Hessarek(S3BZr) & AMP,AML,CST \\
\hline Derby(S3BTa) & Derby(S3BTa) & AMP,AML \\
\hline Hato(S2BMa) & Hato(S2BMa) & SXT \\
\hline OMA,OMB,OMC,OMD-(S11BW1) & OMA,OMB,OMC,OMD-(S11BW1) & CST \\
\hline OMA,OMB,OMC,OMD-(S12BW1) & OMA,OMB,OMC,OMD-(S12BW1) & CST \\
\hline Essen(S10BAg) & Essen(S10BAg) & CST \\
\hline Derby(S1BTa) & Derby(S1BTa) & CST \\
\hline Neg(S3BMa) & $\underline{\mathrm{Neg}(\mathrm{S} 3 \mathrm{BMa})}$ & AMP,AML,AMC,CST \\
\hline
\end{tabular}

Figure 6. Similarity of antibiotic sensitivities of Salmonella isolated from poultry.

\subsection{Distribution of Salmonella Number According a} Function of Their Minimum Inhibitory Concentrations (MIC)

Determination of the Minimum Inhibitory Concentration (MIC) has shown that $100 \%$ (4/4) isolated Salmonella of poultry presented a non-wild phenotype with respect to ampicillin and amoxicillin. 75\% (3/4) of the strains showed maximum resistance (MIC $>256 \mathrm{mg} / \mathrm{l}$ ) to amoxicillin. No strains has shown total resistance to ampicillin (MIC $>256 \mathrm{mg}$ /1) (Table 5). 
Table 5. Distribution of strains resistant to antibiotics isolated from poultry according to their minimum inhibitory concentration (MIC).

\begin{tabular}{|c|c|c|c|c|c|c|c|c|c|c|c|c|c|c|c|c|c|c|c|}
\hline \multirow{2}{*}{ Antibiotics } & \multicolumn{2}{|c|}{$\%$ of strains } & \multicolumn{17}{|c|}{ Resistance > CMI (mg/l) } \\
\hline & Non-wild & Resistances & 1 & 1,5 & 2 & 3 & 4 & 6 & 8 & 12 & 16 & 24 & 32 & 48 & 64 & 96 & 128 & 192 & 256 \\
\hline Amoxicillin & 9,30 & 9,30 & & & & & & & & & & 1 & & & & & & & 3 \\
\hline Ampicillin & 11,43 & 11,43 & & & & & & & & 2 & & 1 & & 1 & & & & & \\
\hline Cefotaxime & 0 & 0 & & & & & & & & & & & & & & & & & \\
\hline Ceftriaxone & 0 & 0 & & & & & & & & & & & & & & & & & \\
\hline Gentamicin & 0 & 0 & & & & & & & & & & & & & & & & & \\
\hline Nalidixic acid & 0 & 0 & & & & & & & & & & & & & & & & & \\
\hline Ciprofloxacin & 0 & 0 & & & & & & & & & & & & & & & & & \\
\hline
\end{tabular}

The empty boxes corresponds to no MIC recorded to these concentration. Number in bold: number of strains presenting a MIC inferior or equal to the smallest tested concentration. The shaded areas correspond to the MICs of the strains considered non-wild by EUCAST. Number in italics: number of strains with a MIC greater than or equal to the highest concentration tested. https://mic.eucast.orgEucast2/SearchController/regShowAll.jsp?T itle $=$ Salmonella $\% 20$ spp.

\section{Discussion}

The poultry sellers (poultry slaughterers) are all men in their majority aged less than thirty years with a low level of education. Similar results were found by Kagambega in Burkina Faso: $100 \%$ of men aged from 15 to 50 years [18] Cardinal in Senegal that found $100 \%$ of men with average age of 38 [19]. Our results have shown that workers in the slaughtering of poultry presented a bad hygiene and a lack of awareness in general hygiene. In Niger, the evisceration of poultry and the gathering visceral tractus are done with hands whith the highest risk of contamination by Salmonella (MEAD, 1980). The scalding by immersion in water has been associated to a risk of contamination by Salmonella for a long time. All these problems have been raised in other studies [18-20]. Microbiological analysis of poultry slaughtering permitted to find case prevalence between $20 \%$ and $69 \%$. Recent studies have shown that poultry are sources for Salmonella. Prevalence found by these studies are respectively $52 \%$ in Ivory Coast, $37 \%$ in Burkina Faso and $33 \%$ in Ibadan, Nigeria. Several factors can intervene in transmitting the Salmonella. In fact, it has proved that flies (Musca domestica L.) are agents of carrying and dissemination of Salmonella in poultry and products derived from birds. In addition, there is a pathology related to poultry called aviary salmonellosis.

Biochemical analysis of 35 isolates of Salmonella resulted in two (2) classes that differed mainly in Inositol ( $\mathrm{INO}^{+}$) degradation. Group 1 is formed by $94.29 \%$ isolates. This metabolic homogeneous dominance that charactizes the majority of isolates $\left(\mathrm{INO}^{+}\right)$and $\left(\mathrm{INO}^{-}\right)$of poultry states a genetic stability of Salmonella non specific host over the time and in different types of identical samples: $S$. Derby, $S$. Typhimurium, $S$. Enteritidis, and $S$. Infantis [21].

Concerning the serotyping of isolated Salmonella of poultry offal, it was observed eight circulating serotypes. The predominance of serotypes varied between $42.37 \%$ for $S$.
Derby $S$. to $1.69 \%$ for $S$. Hessarek and for $S$. Kissangani, each; however $16.95 \%$ of isolates of Salmonella Spp were not serotyped. The major serotypes were identical to those found in Burkina Faso: $S$. Derby $14.57 \%, S$. Chester $8.86 \%$, $S$. Hato: $6.29 \%$ [22]. Contrarily to our results, in Nigeria, the most predominant isolated serotypes of poultry were $S$. Kentucky (16.2\%), S. Poona $(5.66 \%), S$. Elizabethville (4.04\%) and Larochelle/S. Agama (3.77\%) [23]. In Chad, the most frequent isolated laying chicken and pulpit chicken were $S$. Colindale (19\%) followed by $S$. Minnesota (18\%) $S$. Havana and $S$. Riggil (6\% each), $S$. Kottbus and S. Amager $(4.7 \%), S$. Idikan, $S$. Mississippi and $S$. Muenchen (3.6\%)[24]. In Algeria, the most frequently isolated serotypes from meat of cheats poultry and avicole products were $S$. Enteritidis (21.24\%), $S$. Heidelberg (13.04\%), $S$. Infantis, $S$. Ohio, S. Altona $(8.69 \%$ each) [25]. In this study no Salmonella Enteritidis, $S$. Kentucky and $S$. Hadar were found despite that the most predominant serotypes found from poultry in Africa [26]. The study about human infections due to Salmonella in Niger, has showed that the predominant serotypes were respectively $S$. Paratyphi A, $S$. Paratyphi B, $S$. Typhimurim, $S$. Typhi, $S$. Paratyphi C, $S$. Poona, $S$. Paratyphi C, $S$. Bredeney, $S$. Chester and $S$. Derby $[27,1]$. This suggest that even if the poultry offal can be contaminated during the evisceration, they were not the main cause leading to infections of Salmonella to human being.

The sensibility study of isolated strains of poultry towards antibiotics has showed a variable antibacterial activity that didn't reach $(100 \%)$ with the majority of isolates. Kagambéga et al., 2013, did the same remark where most of the strains of Salmonella were sensible to 12 tested antibiotics [22]. Only $10 \%$ of Salmonella isolated show multiresistance. Five profiles of MDR Salmonella have been found. Two $S$. Derby are resistant to two antibiotics (AMP, CST and AMP, AMC). One $S$. Derby and one S. Hessarek are resistant to three antibiotics (AML, AMC, CST and AMP, AML, CST). One Salmonella spp was found to be resistant to four antibiotics (AMP, AML, AMC, CST). These results are very clost those found by Kagambéga et al., 2013 [22].

In this study a resistance of $45 \%$ to colistin has been observed. The measure of CMI (E-TEST $\left.{ }^{\circledR}\right)$ should be done in order to confirm the sensibility or the resistance of these strains to colistin. Results of a study conducted in Brazil have shown that Kirby-Bauer method (The disk-diffusion agar method that tests the effectiveness of antibiotics) is not the most recommend to evaluated the durability to colistin. In 
this study the authors have found $21 \%$ S. enterica strains resistant to colistin Kirby-Bauer method against $4 \%$ of resistance when the CMI has been used [16]. Other studies have described bad results using the diffusion method on disk to detect the resistance to colistin [28].

\section{Conclusion}

A high prevalence of Salmonella has been identified in this study. The lack of hygiene but also the poor practices in the dealing of poultry offal can be one of the contamination source from Salmonella. The results of the evaluation to the sensibility to antibiotics have showed weak resistance to antibiotics of isolated strains of poultry. However, there is a high risk of contamination of these potentially pathogenic germs in humans.

From these facts measures of sensitization and training are necessary with regard to poultry butchers and sellers about the issues of sanitary security of aliments, environmental and personal hygiene. Nigerien authorities could build slaughter houses and markets of poultry to reduce risks of infectious diseases proliferation such as gastroenteritis and alimental toxi-infection.

\section{Acknowledgements}

Authors would like to address a special thank you to the head master of "Société de Transformation Alimentaire «S. T. A Niger» and his team for their financial support in carrying out the activities. This also is the opportunity to thank «Abdou Moumouni University of Niamey, Niger «for the grant allowed for this research.

\section{References}

[1] EFSA Journal (2009). The Community Summary Report on Trends and Sources of Zoonoses and Zoonotic Agents in the European Union in 2007, the EFSA Journal (2009), 223.

[2] David J. (2009). Attribution des cas de salmonelloses humaines aux différentes filières de production animale en France. Adaptabilité et robustesse du modèle bayésien d'attribution par typage microbiologique. In Cellular Biology. Agrocampus - Ecole Nationale Supérieure d'Agronomie de Rennes: Rennes; 278p.

[3] EFSA, (European Food Safety Agence) (2011). The European Union Summary Report on Trends and Sources of Zoonoses, Zoonotic Agents and Food-borne Outbreaks in 2009. EFSA Journal: 9 (3): 2090. [378pp.] doi: 10.2903/j.efsa.2011.2090. Available online: www.efsa.europa.eu/efsajournal.

[4] ECDC (2013). European Centre for Disease Prevention and Control. Annual Epidemiological Report 2013. Reporting on 2011 surveillance data and 2012 epidemic intelligence data. Stockholm: ECDC; 2013. Pp 103.

[5] Humphrey TJ, Mead GC, Rowe B. (1988) Poultry meat as a source of human salmonellosis in England and Wales. Epidemiological overview. Epidemiol. Infect. 1988, 100, 175-184.
[6] Cowden J. M., Chisholm D., O'Mahony M., Lynch D., Mawer S. L., Spain G. E., Ward L., Rowe B. (1989). Two outbreaks of Salmonella Enteritidis phage type 4 infection associated with the consumption of fresh shell-egg products. Epidemiol. Infect. 1989, 103, 47-52.

[7] Humphrey T. J. (1994) Contamination of egg shell and contents with Salmonella Enteritidis: a review. Int. J. Food Microbiol. 1994, 21, 31-40.

[8] Poppe, C. (2000). Salmonella infections in the domestic fowl. In "Salmonella in Domestic Animals." (C. Wray and A. Wray, eds.), pp. 107-132. NY: CAB International, New York.

[9] Hayes S., Nylen G., Smith R., Salmon R. L., Palmer S. R. (1999). Undercooked hens eggs remain a risk factor for sporadic Salmonella enteritidis infection. Commun. Dis. Public. Health., 1999, 2, 66-67.

[10] Huart A et al (2004). La production de la volaille dans le monde et en Afrique, Eco Congo. Agriculture. Pp1.

[11] Baeumler, A. J., Hargis, B. M., and Tsolis, R. M. (2000). Tracing the origins of Salmonella outbreaks. Science 287, 50 52.

[12] Barrow, P. A., Bumstead, N., Marston, K., Lovell, M. A., and Wigley, P. (2004). Faecal shedding and intestinal colonization of Salmonella enterica in in-bred chickens: the effect of hostgenetic background. Epidemiol Infect 132, 117-26.

[13] Keller, L. H., Benson, C. E., Krotec, K., and Ekroade, R. J. (1995). Salmonella Enteritidis colonization of the reproductive tract and forming and freshly laid eggs of chickens. Infect. Immun. 63, 2443-2449.

[14] Moussa AB, Idi A, Benabdeljelil K, 2010. Aviculture familiale rurale au Niger: alimentation et. performances zootechniques. Aviculture Familiale, 19 (1): 3-10.

[15] Idi. A and GANDA I O (2009): Revue du secteur avicole au Niger, Organisation des Nations Unies pour l'Alimentation et l'Agriculture (FAO), pp 3

[16] Morales AS, Fragoso de Araújo J, Túlio de Moura Gomes V, Trindade Reis Costa A, dos Prazeres Rodrigues D, Ferreira TSP (2012). Antibiotic Resistance Associated with Inositol Metabolism in Salmonella from Ontario Cattle. Scientific World Journal: 109795.

[17] Bonny AC, Karou TG, Atobla K, Bohoua LG, Niamkey LS. (2011). Portage de Salmonella au niveau du gésier cru de poulets exposés à la vente à Abidjan, Côte d'Ivoire. J. Appl. Biosci., 47: 3230-3234.

[18] Kagambéga A, Haukka K, Sitonen A, Traore A S, Barro N. (2011) Prevalence of Salmonella enterica and the hygiene indicator. Escherichia coli in raw meat at markets in Ouagadougou, Burkina Faso. J. Food Prot., 74: 1547-1551. Doi: $10.1089 /$ fpd.2011.1071.

[19] Cardinale, E., J. D. Perrier Gros-Claude, F. Tall, E. F. Gueye, and G. Salvat. (2005). Risk factors for contamination of ready-to-eat streetvended poultry dishes in Dakar, Senegal. Int. J. Food Microbiol. 103: 157-165.

[20] Fuzihara, T. O., Fernandes, S. A. \& Franco, B. D. (2000) Prevalence and dissemination of Salmonella serotypes along the slaughtering process in Brazilian small poultry slaughterhouses. Journal of Food Protection, 63: 1749-1753. 
[21] Holt KE, Thomson NR, Wain J, Langridge GC, Hasan R \& Bhutta ZA (2009). Pseudogene accumulation in the evolutionary histories of Salmonella enterica serovars Paratyphi A and Typhi. BMC Genomics 10: 36.

[22] Kagambèga, A. L., Taru, L., Aulu, L., Traoré, A. S., Barro, N., Siitonen, A., Haukka, K., (2013): Prevalence and characterization of Salmonella enterica from the feces of cattle, poultry, swine and hedgehogs in Burkina Faso and their comparison to human Salmonella isolates. BMC Microbiology, 13: 253 http://www.biomedcentral.com/14712180/13/253. 22.

[23] Fagbamila IO, Barco L, Mancin M, Kwaga J, Ngulukun SS, Zavagnin P, et al. (2017) Salmonella serovars and their distribution in Nigerian commercial chicken layer farms. PLoS ONE 12 (3): e0173097. doi: 10.1371/journal. pone.0173097.

[24] Tabo DA, Diguimbaye CD, Granier SA, Moury F, Brisabois A, Elgroud R, Millemann Y. (2013). Prevalence and antimicrobial resistance of non-typhoidal Salmonella serotypes isolated from laying hens and broiler chicken farms in N'Djamena, Chad. Vet Microbiol. 2013 Sep 27; 166 (1-2): 293-8. doi: 10.1016/j.vetmic.2013.05.010.

[25] Mezali L, Taha-Mossadak Hamdi (2011). Prevalence and antimicrobial resistance of Salmonella spp. isolated from raw poultry meat and poultry products in Algiers (Algeria). EggMeat Symposia 2011. High National Veterinary School, BP 161 El-Harrach, Algiers, Algeria.

[26] Alio Sanda A, Samna Soumana O, Inoussa Maman M, Diallo Bouli A, Bakasso Y. (2017). Prévalence Et Diversité De Salmonella En Afrique: Analyse Qualitative Et Quantitative European Scientific Journal Vol.13, No.30 ISSN: 1857-7881. URL: http://dx.doi.org/10.19044/esj.2017.v13n30p250.

[27] Alio Sanda A, Samna S. O, Bakasso Y. (2018) Epidemiology, diversity and resistance to antibiotics in Salmonella strains isolated from human in two cities of Niger Republic. International Journal of Current Research. 10, (02), 65364-65370.

[28] Boyen F, Vangroenweghe F, Butaye P, et al., (2010) Disk prediffusion is a reliable method for testing colistin susceptibility in porcine E. coli strains. Veterinary Microbiology. 2010; 144 (3-4): 359-362. 